\title{
Isotope Ratio Analysis by HRGC-MS of Monoterpene Hydrocarbons from Citrus Essential Oils
}

\author{
Atsushi Satake, ${ }^{1,2, \dagger}$ Akitoshi Une, ${ }^{1}$ Takao Ueno, ${ }^{1}$ Hiroyuki Ukeda, ${ }^{1}$ \\ and Masayoshi SAwAmURA ${ }^{1}$ \\ ${ }^{1}$ Department of Bioresources Science, Faculty of Agriculture, Kochi University, Nankoku, \\ Kochi 783-8502, Japan \\ ${ }^{2}$ Nagaoka Perfumery Co., Ltd., 3-30, 1-chome, Itsukaichi, Ibaraki-City, Osaka 567-0005, Japan
}

Received October 18, 2002; Accepted November 12, 2002

The isotope ratio of monoterpene hydrocarbons in citrus essential oils of different origins was measured by ordinary high-resolution gas chromatography-mass spectrometry (HRGC-MS). The isotope ratio (Ir) was determined by the ratio of the isotope peak intensity $(m / z$ 137) to the molecular mass peak intensity $(m / z$ 136) of the monoterpene hydrocarbons. The accuracy of Ir was examined by measuring monoterpene hydrocarbon standards and ${ }^{13} \mathrm{C}$-labeled compounds. The isotope fingerprints based on the values of monoterpene hydrocarbons from lemon, lime and yuzu essential oils were determined. These citrus essential oils were also discriminated by a principal component analysis of their Ir data. The characteristic vectors showed that $\alpha$-terpinene, $\beta$-pinene and $\beta$-phellandrene were important components for distinguishing between the citrus species. It is suggested that this technique will be applicable to evaluate the quality, genuineness and origin of citrus fruits and their products.

Key words: citrus essential oil; isotope effect; isotope ratio; HRGC/MS; monoterpene hydrocarbon

The natural abundance of the isotopes of each element is distributed in a given ratio. Plants on the Earth first convert solar energy into biochemical energy; the food chain starts from plants. Higher plants fix $\mathrm{CO}_{2}$ by the Calvin-Benson cycle to biosynthesize various organic compounds for their constituents. ${ }^{1)}$ It is known that the enzyme, ribulose-1,5diphosphate carboxylase, differentiates a small mass difference between ${ }^{12} \mathrm{CO}_{2}$ and ${ }^{13} \mathrm{CO}_{2}$ when it fixes $\mathrm{CO}_{2}$ in the atmosphere. This function is the so-called "isotope effect". It has also been stated that this effect could be achieved by every kind of enzyme involved in biosynthetic and metabolic pathways. ${ }^{2}$ Thus, the isotope effect should also occur in the essential oils comprising terpene compounds. Every species, variety or strain of plant has substantially in- dividual characteristics. Even among the same cultivar, different growing conditions such as the annual atmosphere and moisture, soil and fertilizers bring about small but appreciable differences in composition.

Citrus fruits are widely cultivated between the tropical and temperate zones in both the northern and southern hemispheres. The citrus fruit is one of the most important commercial crops, since it provides us with a pleasant taste, flavor and fragrance. It is said that there are thousands of varieties of citrus in the world. The extensive research on citrus flavor has been reviewed. ${ }^{3,4)}$ It has recently become commercially important to evaluate the property, quality, origin and genuineness of raw and processed products. Flavor analysis is a good means of revealing the characteristics of products, although it may be difficult to make sufficient discrimination among the same or similar cultivars by means of a general flavor compositional analysis by GC and GC-MS.

Faulharber et $a .^{5,6)}$ and other researchers ${ }^{7-9)}$ have described how the determination of the isotope values of constituents is of increasing importance, especially in view of the demand for authenticity control and origin determination of essential oils and foods. To determine isotope values, gas chromatography-isotope ratio mass spectrometry (GCIRMS) has been used, although not widely. The present authors ${ }^{10)}$ have studied the possibility of a more convenient and common means of analysis of isotope values, based on the isotope peak in the mass spectrum of a compound. The present study focuses on the development of a new analytical method for the differentiation of quality in commercial citrus oils of various origins.

\section{Material and Methods}

Materials. The samples of lemon and lime essential oils were commercial products for flavor materials.

${ }^{\dagger}$ To whom correspondence should be addressed. Tel: +81-88-864-5184; Fax: +81-88-864-5200; E-mail: gcd03100@nifty.ne.jp 
Yuzu fruits were collected from 10 local wholesale markets from northern to southern Japan in November 1999, and their cold-pressed oils (CPO) were prepared as described in a previous paper. ${ }^{10)}$ Lemon CPO was prepared from commercially sold fruits by the same method. Authentic chemicals for mass spectrometry were obtained from the commercial sources mentioned previously. ${ }^{11)}$

Gas chromatography-mass spectrometry (GC$M S)$. Gas chromatography combined with mass spectrometry was used for identifying the volatile components. The analysis was carried out with a Shimadzu GC-17A linked with a Shimadzu QP-5050 at an MS ionization voltage of $70 \mathrm{eV}$, accelerating voltage of $1500 \mathrm{~V}$, and ion source temperature of $250^{\circ} \mathrm{C}$. The GC column was DB-Wax fused-silica capillary type (60 $\mathrm{m} \times 0.25 \mathrm{~mm}$ i.d., $0.25 \mu \mathrm{m}$ film thickness; J \& W Scientific, Folsom, CA, U.S.A). The column temperature was programmed from $70^{\circ} \mathrm{C}$ ( 2 min hold) to $100^{\circ} \mathrm{C}$ at a rate of $2^{\circ} \mathrm{C} / \mathrm{min}$. The column was cleaned by heating to $230^{\circ} \mathrm{C}$ before each run. The injector temperature was $250^{\circ} \mathrm{C}$, and helium was used as the carrier gas at a flow rate of $0.8 \mathrm{ml} / \mathrm{min}$. An oil sample of $0.2 \mu \mathrm{l}$ was injected at a split ratio of $1: 50$.

Identification of the components. Each component was initially identified by the GC retention index and the NIST library connected to the QP-5050 mass spectrometer, as described in previous papers. ${ }^{10,11)} \mathrm{A}$ JNM-LA400 spectrometer (Jeol, Tokyo) was employed for recording the ${ }^{13} \mathrm{C}-\mathrm{NMR}$ spectra, $\mathrm{CDCl}_{3}$ being used as a solvent.

Determination of the isotope ratio. The following 10 monoterpene compounds were examined in the determination of isotope ratios: $\alpha$-pinene, $\beta$-pinene, sabinene, myrcene, $\alpha$-phellandrene, $\alpha$-terpinene, limonene, $\gamma$-terpinene, $\beta$-phellandrene and terpinolene. Selected ion monitoring (SIM) of GC-MS was performed in order to estimate the intensities of the ion peaks of each molecule $(m / z 136)$ and of its isotope $(m / z$ 137). The total intensity of each compound was regulated to achieve about $8.0 \times 10^{7}$ in $\mathrm{MS}$, the mass spectrometry scanning interval being $0.1 \mathrm{sec}$. The isotope ratio (Ir) of each peak was calculated by the following equation:

$$
\begin{aligned}
\mathrm{Ir}= & (\text { Intensity of an isotope peak of } m / z \text { 137) } \\
& /(\text { Intensity of a molecular peak of } m / z 136) \\
& \times 100
\end{aligned}
$$

where the intensity is the mean value from quintuplicate measurements.

Synthesis of esters. The ${ }^{13} \mathrm{C}$-labeled esters were synthesized by a conventional method. ${ }^{12)}$ A solution of $9 \mathrm{mmol}$ of butanol, pentanol, hexanol, heptanol,
Table 1. Components of the ${ }^{13} \mathrm{C}$-Labeled Ester Mixture

\begin{tabular}{lcc}
\hline \hline Compound & $\begin{array}{c}\text { Conc. } \\
\%(\mathrm{w} / \mathrm{w})\end{array}$ & $\begin{array}{c}\text { Molecular } \\
\text { weight }\end{array}$ \\
\hline Pentyl acetate & 2.36 & 131.2 \\
Hexyl acetate & 2.64 & 145.0 \\
Heptyl acetate & 2.96 & 159.2 \\
Octyl acetate & 3.23 & 173.3 \\
Nonyl acetate & 3.54 & 187.3 \\
Decyl acetate & 3.80 & 201.3 \\
\hline
\end{tabular}

octanol, nonanol or decanol in benzene was mixed with $82 \mathrm{mmol} 1{ }^{13} \mathrm{C}$-acetic acid. The reaction mixture was refluxed for $1.5 \mathrm{hr}$ with a small amount of $p$-toluene sulfonic acid. The reaction proceeded almost perfectly, and mixtures containing the esters of the 5-10 carbon number at $2.6-3.8 \%(\mathrm{w} / \mathrm{w})$ were obtained (Table 1). The synthesized ${ }^{13} \mathrm{C}$-labeled esters were determined by GC and GC-MS. Non-labeled esters were synthesized as well.

Synthesis of limonene. 4-Acetyl-1-methylcyclohexene was synthesized by the method described by Lutz et al. ${ }^{13)}$ and Fray et al. ${ }^{14)}$ Ninety mmol of $\mathrm{SnCl}_{4}$ was added to $120 \mathrm{ml}$ of benzene while stirring at $3{ }^{\circ} \mathrm{C}$, and then $550 \mathrm{mmol}$ of isoprene was added. The reaction mixture was added to $500 \mathrm{mmol}$ of methyl vinyl ketone over a 15 -min period, and then stirred continuously for $2 \mathrm{hr}$ at $5-10^{\circ} \mathrm{C}$. The mixture was successively washed with an $\mathrm{NaCl}$ aq. solution and $\mathrm{KOH}$ aq. solution, and dried with sodium sulfate. After drying, the mixture was evaporated to $31.4 \mathrm{~g}$ (a yield of $45.4 \%$ ). Identification was carried out by GC and GC-MS. The purity of 4-acetyl-1-methylcyclohexene was $96 \%$ by GC, containing $4 \%$ of 3 -acetyl-1methylcyclohexene.

${ }^{13}$ C-Labeled limonene, 1-methyl-4-(1-methyl-(2$\left.{ }^{13} \mathrm{C}\right)$-ethenyl)-cyclohexene, was synthesized by means of the Witting-reaction. ${ }^{15}$ The labeling reagent, $4.9 \mathrm{mmol}^{13} \mathrm{CH}_{3} \mathrm{P}\left(\mathrm{C}_{6} \mathrm{H}_{5}\right)_{3} \mathrm{I}$, was added at $20^{\circ} \mathrm{C}$ over $5 \mathrm{~min}$ to a solution of $4.9 \mathrm{mmol} \mathrm{NaH}$ in $5 \mathrm{ml}$ of DMSO, which had been prepared while stirring at below $70^{\circ} \mathrm{C}$, and the mixture stirred for $20 \mathrm{~min}$. After adding $5.0 \mathrm{mmol}$ of acetyl-1-methylcyclohexene at $20^{\circ} \mathrm{C}$ over $5 \mathrm{~min}$, the reaction mixture was stirred for $2.5 \mathrm{hr}$ at room temperature. Extraction was performed with pentane and, after drying with sodium sulfate, the solvent was removed to obtain the final product of $0.14 \mathrm{~g}$ (a yield of $20.9 \%$ ).

\section{Results and Discussion}

Accuracy of the isotope ratio by ordinary GC-MS In principle, it is possible to obtain the isotope ratio from MS data. The authors have previously shown, in fact, a practical use for the isotope ratio from mass spectrometry. ${ }^{10)}$ However, more detailed analytical conditions need to be found to achieve 


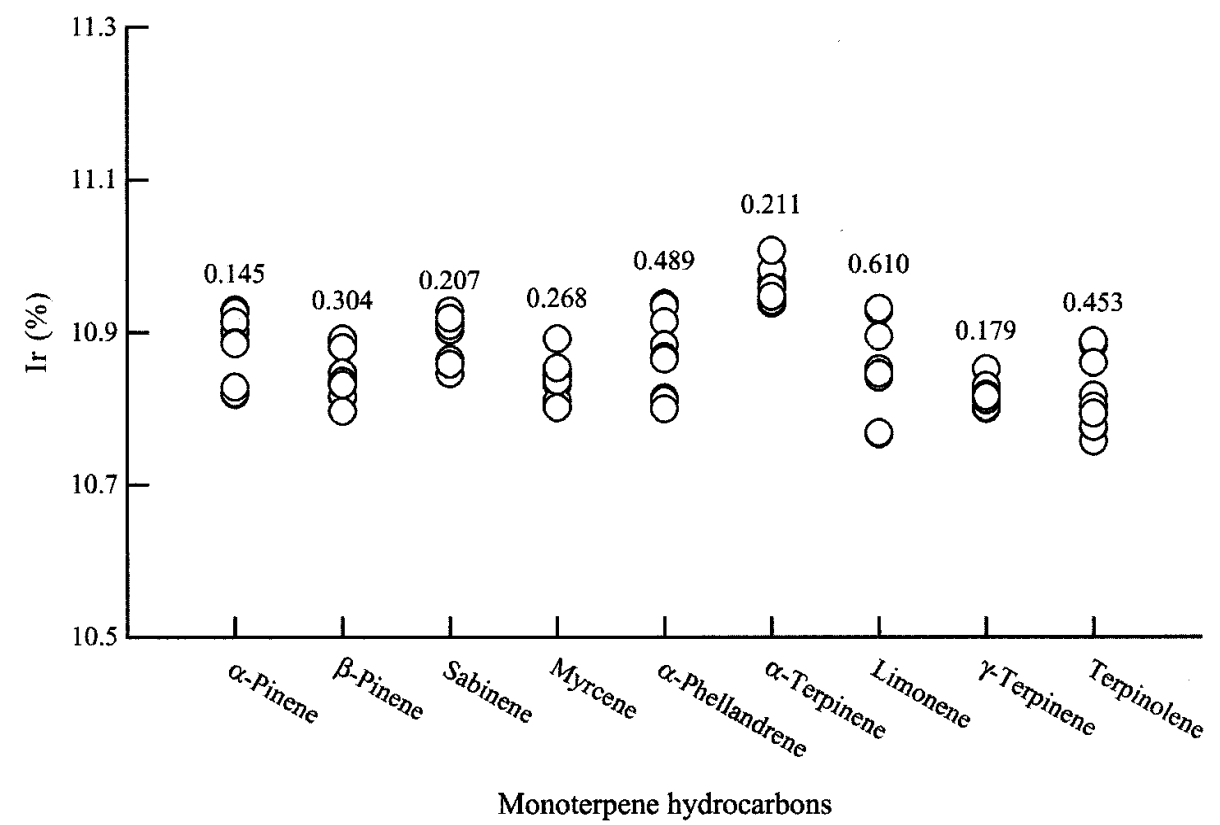

Fig. 1. Ir Values of the Monoterpene Hydrocarbon Standards.

The figures above the symbols show the coefficient of variation.

more precise measurement. The intensity of each molecular ion peak is not very strong. In addition, the isotope peak is approximately $10 \%$ of that of the molecular ion peak in the case of monoterpene hydrocarbons in citrus essential oils.

The repeatability of the Ir values for various monoterpene hydrocarbons was examined. The concentrations of the standard samples for GC-MS of $\alpha$-pinene, $\beta$-pinene, sabinene, myrcene, $\alpha$-phellandrene, $\alpha$-terpinene, limonene, $\gamma$-terpinene and terpinolene were within the range of $0.5-1.8 \%(\mathrm{w} / \mathrm{w})$. The Ir value for each monoterpene hydrocarbon was plotted in Fig. 1, where the coefficient of variation (CV) is also presented. These Ir values only seem to vary over a narrow range, since their CVs were not more than $0.61 \%$ (limonene).

4-Acetyl-1-methylcyclohexene had a purity of $95 \%$ by GC, and contained 5\% 1-methyl-3-(1-methyl-(2${ }^{13} \mathrm{C}$ )-ethenyl)-cyclohexene. It was confirmed that the $\delta 108.30$ (C-10) signal was increased. The $m / z$ and peak intensity (\%) data for the fragment in the mass spectrum were as follows: MS (non-labeled limonene) $m / z 136\left(18, \mathrm{M}^{+}\right), 107$ (19), 94 (27), 93 (67), 92 (23), 78 (30), 68 (100), 67 (78), 52 (29); MS ( ${ }^{13} \mathrm{C}$-labeled limonene) $m / z 137\left(18, \mathrm{M}^{+}\right), 108$ (19), 95 (24), 94 (35), 93 (51), 79 (19), 68 (100), 67 (52), 52 (27). The $\delta$ values from the ${ }^{13} \mathrm{C}-\mathrm{NMR}$ spectrum of each carbon in the ${ }^{13} \mathrm{C}$-labeled limonene were as follows: $\delta$ 133.75 (C-1), $\delta 27.92$ (C-2), $\delta 30.59$ (C-3), $\delta 41.08$ (C-4), $\delta 30.81$ (C-5), $\delta 120.67$ (C-6), $\delta 23.45$ (C-7), $\delta$ 150.25 (C-8), $\delta 20.80$ (C-9), $\delta 108.30$ (C-10).

The relationship between the ratio of the isotope peak intensity to the molecular mass peak intensity (Ir) and the isotopic ratio of ${ }^{13} \mathrm{C}$ were then examined.
${ }^{13} \mathrm{C}$-labeled esters and limonene were added to nonlabeled compounds, and the Ir values were measured. As shown in Fig. 2, a strong linear relationship was observed between the Ir value and the ${ }^{13} \mathrm{C}$ isotopic ratio. The $\mathrm{R}^{2}$ value for the esters was greater than 0.96 , except for decyl acetate. The accuracy with decyl acetate was rather low $\left(R^{2}=0.85\right)$, because the intensity of the molecular ion peak tended to decrease with increasing molecular weight. The difference in the intercept and gradient between octyl acetate and the other acetates may be explained by the difference between the isotope ratio of octanol and those of the other alcohols.

These results show that the reproducibility for determining the peaks of the molecular ion and its isotope by ordinary GC-MS is satisfactory and applicable for practical use. It is expected that this method of isotope analysis can also be applied to organic compounds which have a wide range of molecular weight.

Ir analysis of monoterpene hydrocarbons from citrus essential oils

The isotope ratio analysis was carried out on various kinds of citrus essential oils, including commercial CPO of five lemon oils and five lime oils, an artificial lemon flavor product, a lemon CPO and ten yuzu CPO from Japan. The isotope effect was found to be influenced by exogenous factors such as differences in location, climate and cultivation conditions. ${ }^{2,6)}$ When the Irs of monoterpene hydrocarbons were divided by the Ir of one compound, limonene, of each essential oil (modified Ir), the influence on isotope discrimination by $\mathrm{CO}_{2}$ fixation was eliminat- 

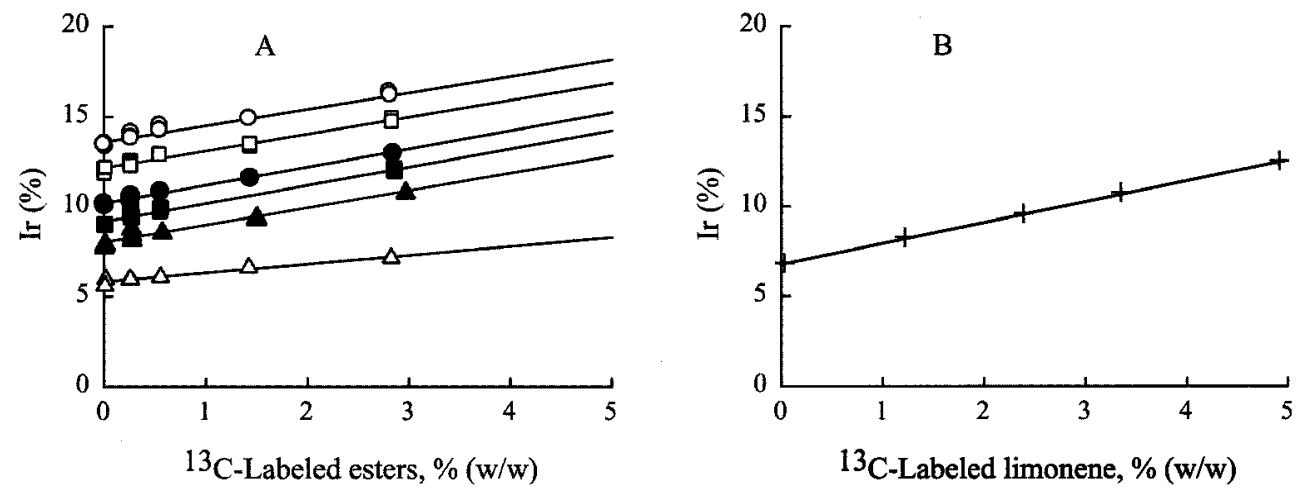

Fig. 2. Ir Values of the ${ }^{13} \mathrm{C}$-Labeled Compounds.

A ${ }^{13} \mathrm{C}$-Labeled Esters

ム Pentyl acetate, $\mathrm{y}=8.053+0.961 \mathrm{x}, \mathrm{R}^{2}=0.958$, - Hexyl acetate, $\mathrm{y}=9.196+1.016 \mathrm{x}, \mathrm{R}^{2}=0.984$, - Heptyl acetate, $\mathrm{y}=$ $10.224+1.000 x, R^{2}=0.992, \triangle$ Octyl acetate, $y=5.871+0.484 x, R^{2}=0.980, \square$ Nonyl acetate, $y=12.19+0.949 x, R^{2}=0.976, \circ$ Decyl acetate, $\mathrm{y}=13.63+0.917 \mathrm{x}, \mathrm{R}^{2}=0.849$

B ${ }^{13} \mathrm{C}$-Labeled Limonene

+ Limonene, $\mathrm{y}=10.047+0.866 \mathrm{x}, \mathrm{R}^{2}=1.000$.

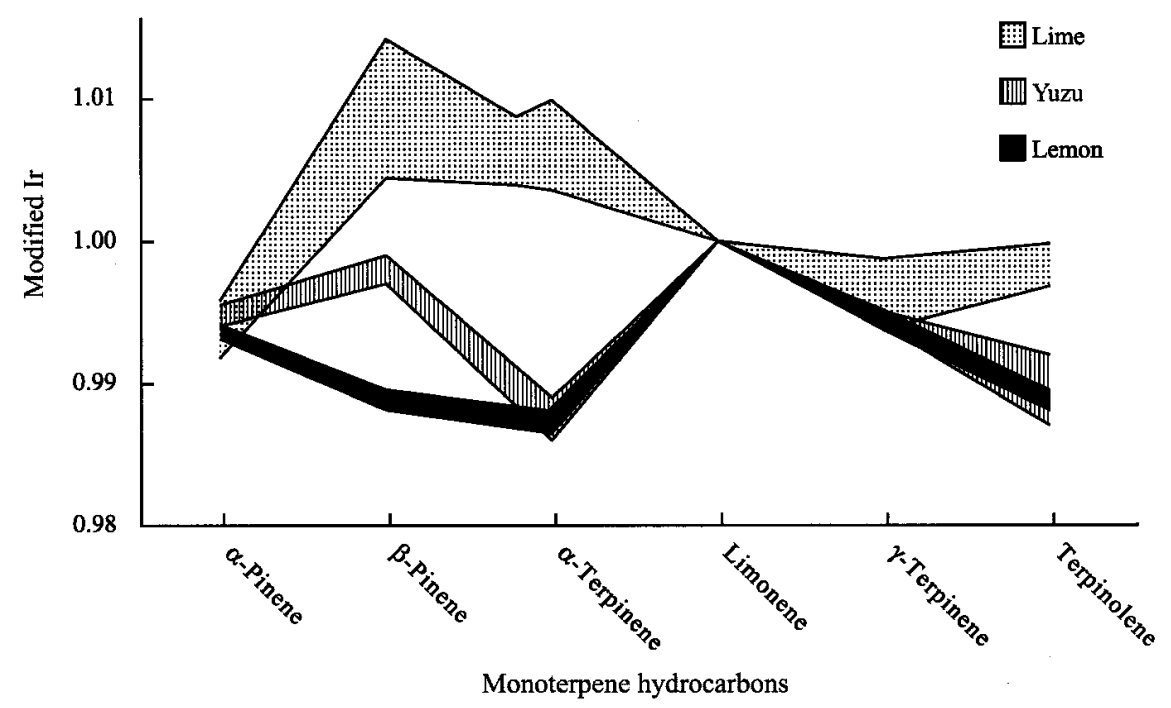

Fig. 3. Modified Ir Values of the Monoterpene Hydrocarbons from Citrus Oils.

ed. $\left.{ }^{6}\right)$ This calculation will result in Ir patterns based on secondary metabolites, showing the specific pattern of each plant species. As shown in Fig. 3, a characteristic fingerprint was obtained for each citrus species. The composition of citrus essential oils generally depends on the variety or species. Thus, the six monoterpene hydrocarbons were selected as common constituents of the three kinds of CPO for performing the isotope ratio analysis. These fingerprints of lemon, lime and yuzu were clearly distinct, the fingerprint band of lime being broader than that of yuzu and lemon. This may have been due the fact that the lime oil sample was a mixture of products from various localities, varieties and/or distillate oil from juice. The fingerprint of yuzu CPO agreed with the one reported previously. ${ }^{10)}$

\section{Multivariate analysis}

The modified Ir data for monoterpene hydrocarbons from the three species of citrus oils were subjected to a multivariate analysis. According to principal component (PC) analysis, the citrus essential oils examined were clearly discriminated, with $93.3 \%$ of the accumulation contribution ratio of both PC1 and PC2 (Fig. 4A). As shown in Fig. 4B, $\beta$-pinene (PC1, 0.530 $\cdot \mathrm{PC} 2,-0.80)$, $\alpha$-terpinene $(0.685 \cdot 0.062)$ and $\beta$-phellandrene $(0.324 \cdot 0.810)$ were large for the absolute value of the eigenvector of monoterpene system hydrocarbons, followed by terpinolene $(0.367 \cdot-0.010)$. These compounds greatly contributed to the modified Ir discrimination of the citrus essential oils.

The cluster analysis is shown Fig. 5; all of the essential oils, except for lime oil E, were classified into the species clusters. Regarding the yuzu oils, it is 

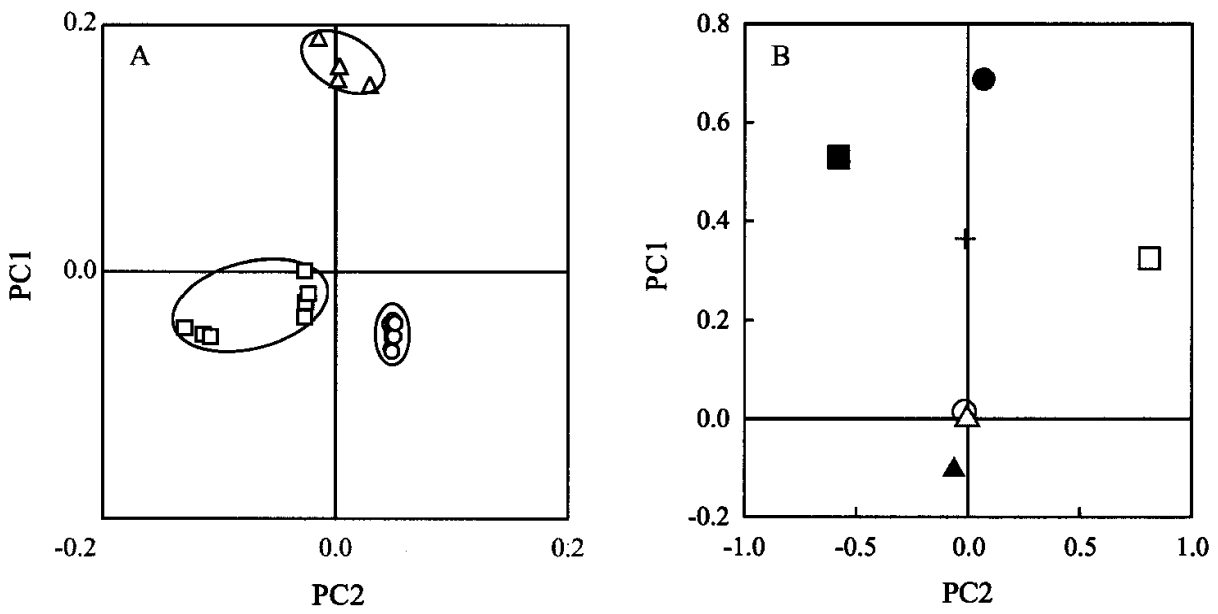

Fig. 4. Principal Component Analysis of the Modified Ir Values of the Monoterpene Hydrocarbons from Citrus Oils.

A Principal component scores of citrus oils

$\triangle$ lime, $\bigcirc$ yuzu, $\square$ lemon.

B Characteristic vectors of monoterpene hydrocarbons

$\Delta \alpha$-pinene, $\boldsymbol{\Delta} \beta$-pinene, $\bullet \alpha$-terpinene, $\triangle$ limonene, $\square \beta$-phellandrene, $\bigcirc \gamma$-terpinene, + terpinolene.

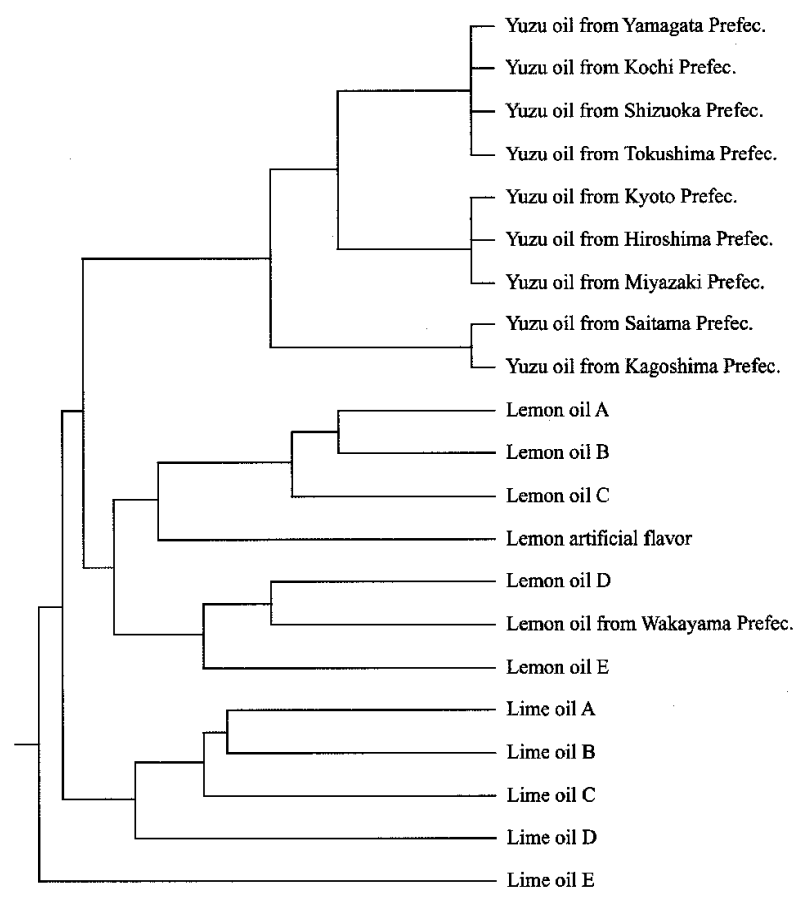

Fig. 5. Cluster Analysis of the Modified Ir Values of the Monoterpene Hydrocarbons from Citrus Oils.

noteworthy that the essential oils from Yamagata, Kochi, Shizuoka and Tokushima prefectures, which each had a high sensory evaluation, were classified into the same cluster, which is in accordance with the findings in our previous report. ${ }^{10)}$ The artificial lemon flavor essence and the lemon CPO from Wakayama Prefecture in Japan were classified into the same cluster as the commercial lemon samples.

These results suggest that, in addition to an enantiomeric analysis, ${ }^{16,17)}$ this analytical method can be applied to evaluate the genuineness of essential oils.
Furthermore, it is expected that this technique of isotope ratio analysis will be applicable to evaluate the origin of citrus essential oils and their products, and also to specify organic compounds from natural resources.

\section{References}

1) Park, R., and Epsten, S., Carbon isotope fractionation during photosynthesis. Geochim. Cosmochim. Acta, 21, 110-126 (1960).

2) O'Leary, M. H., Carbon isotope fractionation in plants. Phytochemistry, 20, 553-567 (1981).

3) Shaw, P. E., Review of quantitative analyses of citrus essential oils. J. Agric. Food Chem., 27, 246-257 (1979).

4) Sawamura, M., Volatile components of essential oils of the Citrus genus. In "Recent Research Developments in Agricultural and Food Chemistry" vol. 4, ed. Pandalai, S. G., Research Signpost, Trivandrum, India, pp. 131-164 (2000).

5) Faulharber, S., Hener, U., and Mosandl, A., GCIRMS analysis of mandarin essential oils. $1 . \delta^{13} \mathrm{C}_{\mathrm{PDB}}$ and $\delta{ }^{15} \mathrm{~N}_{\text {AIR }}$ values of methyl $N$-methyl-anthranilate. J. Agric. Food Chem., 45, 2579-2583 (1997).

6) Faulharber, S., Hener, U., and Mosandl, A., GCIRMS analysis of mandarin essential oils. $2 . \delta^{13} \mathrm{C}_{\mathrm{PDB}}$ values of flavor components. J. Agric. Food Chem., 45, 4719-4725 (1997).

7) Faber, B., Krause, B., Dietrich, A., and Mosandl, A., Gas chromatography-isotope ratio mass spectrometry in the analysis of peppermint oil and its importance in the authenticity control. J. Essent. Oil Res., 7, 123-131 (1995).

8) Frank, C., Dietrich, A., Kremer, U., and Mosandl, A., GC-MS in the authenticity control of the essential oil of Coriandrum sativum L. J. Agric. Food Chem., 43, 1634-1637 (1995).

9) Hener, U., Faulhaber, S., Kreis, P., and Mosandl, 
A., On the authenticity evaluation of balm oil (Melissa officinalis L.). Pharmazie, 50, 60-62 (1995).

10) Sawamura, M., Ito, T., Une, A., Ukeda, H., and Yamazaki, Y., Isotope ratio by HRGC-MS of Citrus junos Tanaka (Yuzu) essential oils: $m / z$ 137/136 of terpene hydrocarbons. Biosci. Biotechnol. Biochem., 12, 2622-2629 (2002).

11) Choi, H. S., and Sawamura, M., Volatile flavor components of ripe and overripe ki-mikans (Citrus flaviculpus Hort. ex Tanaka) in comparison with hyuganatsu (Citrus tamurana Hort. ex Tanaka). Biosci. Biotechnol. Bichem., 65, 48-55 (2001).

12) Weissberger, A., and Kibler, C., Methyl pyruvate. $J$. Org. Synth., 2, 610-613 (1943).

13) Lutz, E. F., and Bailey, G. M., Regulation of structural isomerism in simple Diels-Alder adducts. $J$. Amer. Chem. Soc., 86, 3899-3901 (1964).

14) Fray, G. I., and Robinson, R., Catalysis of the Diels-
Alder reaction. J. Amer. Chem. Soc., 83, 249 (1961).

15) Reichert, S., Fischer, D., Asche, S., and Mosandl, A., Stable isotope labeling in biosynthetic studies of dill ether, using enantioselective multidimensional gas chromatography, online coupled with isotope ratio mass spectrometry. Flavour Fragr. J., 15, 303-308 (2000).

16) Cotroneo, A., d'Alcontres, I. S., and Trozzi, A., On the genuineness of citrus essential oils. Part XXXIV. Detection of added reconstituted bergamot oil in genuine bergamot essential oil by high-resolution gas chromatography with chiral capillary columns. Flavour Fragr. J., 7, 15-17 (1992).

17) Mitiku, S. B., Sawamura, M., Njoroge, S. M., and Koaze, H., Analytical discrimination of the coldpressed oils of mandarins and their hybrids. J. Essent. Oil Res., 14, 196-202 (2002). 